International Journal of Molecular Medicine and Advance Sciences 6 (2): 26-30, 2010

ISSN: $1813-176 \mathrm{X}$

(C) Medwell Journals, 2010

\title{
Investigation of Anti-Inflammatory, Analgesic and Antipyretic Properties of Madhuca indica GMEL
}

\author{
Neha Shekhawat and Rekha Vijayvergia \\ Department of Botany, Plant Pathology and Biochemistry Laboratory, \\ University of Rajasthan, Jaipur, India
}

\begin{abstract}
The crude methanolic extract of Madhuca indica (Sapotaceae) at 50, 100 and $200 \mathrm{mg} \mathrm{kg}^{-1} \mathrm{body}$ weight were evaluated for anti-inflammatory, analgesic and antipyretic activities in male wistar rats. Anti-inflammatory activity was studied by using carrageenan induced oedema right hind paw volume while the analgesic effect was evaluated using acetic acid-induced abdominal pains i.e., nociception response. The brewer's yeast-induced pyrexia model was used for antipyretic investigation. Phytochemical screening of the alcoholic extract revealed the presence of tannins, flavonoids, steroids, terpenes, cardiac glycosides and saponins. The extract at all the doses used and the indomethacin significantly inhibited carrageenan induced inflammation in a manner that was not dose dependent. The extract reduced the acetic acid induced pain licking. While the 50 and $100 \mathrm{mg} \mathrm{kg}^{-1}$ body weight of the extract reduced the brewer's yeast provoked elevated body temperature in rats after $60 \mathrm{~min}$ that of $200 \mathrm{mg} \mathrm{kg}^{-1}$ body weight manifested from $30 \mathrm{~min}$. The results suggest a potential benefit of $M$. indica methanolic extract in treating conditions associated with inflammation, pain and fever. These properties might be adduced to the presence of the phytoconstituents.
\end{abstract}

Key words: Madhuca indica, anti-inflammatory, analgesic, antipyretic, rats, extract

\section{INTRODUCTION}

Medicinal plants are believed to be an important source of new chemical substances with potential therapeutic effects. Herbalism is a traditional medicinal or folk medicine practice based on the use of plants and plant extracts (Acharya and Shrivastava, 2008). Many plants synthesize substances that are useful to the maintenance of health in humans and other animals. These include aromatic substances, most of which are phenols or their oxygen-substituted derivatives such as tannins. Many of the herbs and spices used by humans to season food yield useful medicinal compounds (Lai and Roy, 2004; Tapsell et al., 2006). Herbal therapy is used to treat a large variety of ailment and symptoms e.g., inflammation fever and pain; however there are no adequate experimental evidences about their effectiveness (Kuhn and Winston, 2000; Golshani et al., 2004; Monsef-Esfahani et al., 2004).

Madhuca indica Gmel. (Koenig) belongs to the family Sapotaceae commonly known as mahua. Mahua is a large, shady, deciduous tree doting much of the central Indian landscape, both wild and cultivated. The tree is valued for its oil-bearing seeds and flowers which are utilized for alcoholic beverage production. Mahua seeds are of economic importance as they are good source of edible fats (Ramadan et al., 2006). The distilled juice of the flower is considered a tonic, both nutritional and cooling and also in treatment of helminthes, acute and chronic tonsillitis, pharyngitis (Nadkarni, 1954) as well as bronchitis (Varier, 1995). The leaves are applied as a poultice to relieve eczema.

Previous phytochemical studies on Madhuca indica included characterization of sapogenins, triterpenoids, steroids, saponins, flavonoids and glycosides (Yosiokal et al., 1974; Yoshikawa et al., 2000).

The medicinal properties attributed to this plant are stimulant, demulcent, emollient, heating and astringent. The bark is a good remedy for itch, swelling, fractures and snake-bite poisoning, internally employed in diabetes mellitus. In view of this collection and utilization of different parts of mahua. So an ettempt was made to investigate the pharmacological activities of Madhuca indica alcoholic extract. To the best of the knowledge this is the first report on anti-inflammatory, analgesic and antipyretic properties of crude Methanolic Extract of Madhuca Indica (MEMI).

Corresponding Author: Neha Shekhawat, Department of Botany, Plant Pathology and Biochemistry Laboratory, University of Rajasthan, Jaipur, India 


\section{MATERIALS AND METHODS}

Plant material and extraction: Aerial part of, $M$. indica was collected freshly from the different areas and identified by the herbarium of Botany Department, Rajasthan University and voucher specimens were deposited there. For methanolic extraction powdered dry plant material ( $50 \mathrm{~g}$ ) was extracted with $100 \mathrm{~mL}$ methanol for $24 \mathrm{~h}$ by using Soxhlet apparatus. The extracts were filtered and concentrated under vaccum sounding apparatus for $30 \mathrm{~min}$. All the extracts were stored at $4^{\circ} \mathrm{C}$.

Experimental animals: In breed Albino male Wistar rats (150-200 g) were used for the experiments. All the animals were obtained from the Zoology department, University of Rajasthan, Jaipur. The animals were maintained under standard environmental conditions and fed with standard diet and water ad libitum. Approval from the institutional animal ethical committee for usage of animals in the experiments was obtained.

Drugs and chemicals: The drugs and fine chemicals were purchased from Sigma Chemical Co., St. Louis, USA. All other chemicals and solvents were obtained from local firms (India) and were of highest purity and analytical grade.

\section{Acute inflammation study}

Carrageenan-induced paw oedema in rats: Pedal inflammation in male Wistar rats (150-200 g) was produced according to the method described earlier (Winter et al., 1962). An injection (s.c.) was made of $0.1 \mathrm{~mL}$ of $1 \%$ carrageenan into the right paw of each rat under the sub plantar aponeurosis.. The rats were divided into 5 groups $(\mathrm{n}=6)$. The different groups were treated with MEMI $\left(50,100\right.$ and $200 \mathrm{mg} \mathrm{kg}^{-1}$, p.o.) in domethacin ( $10 \mathrm{mg} \mathrm{kg}^{-1}$, p.o.) and control vehicle per oral. The paw volume was measured immediately after carrageenan injection and at 1-5 $\mathrm{h}$ intervals after the administration of the edematogenic agent using a plethysmograph apparatus up to the anatomical hairline on lateral malleolus (Goldenberg and IIse, 1977) and compared with the control animals which received only the vehicle. The inhibitory activity was calculated according to the following formula (Chu and Kovacs, 1977).

$$
\text { Percentage inhibition }=\frac{\mathrm{Vc}-\mathrm{Vt}}{\mathrm{Vc}} \times 100
$$

Where:

$\mathrm{Vc}=$ Edema volume of control

$\mathrm{Vt}=$ Edema volume of test

\section{Antinociceptive activity}

Effect on acetic acid-induced writhing in mice: Analgesic activity was evaluated on the acetic acid induced writhing according to Koster et al. (1959). The writhes were induced by intra-peritoneal injection of $0.6 \%$ acetic acid $(\mathrm{v} / \mathrm{v})\left(10 \mathrm{~mL} \mathrm{~kg}{ }^{-1}\right)$. Three different doses $(50,100$ and $200 \mathrm{mg} \mathrm{kg}^{-1}$ ) of the MEMI were administered orally to different groups of 6 animals each, $30 \mathrm{~min}$ before chemical stimulus. the number of writhes during the following $30 \mathrm{~min}$ period was observed after acetic acid injection. Antinociception (analgesia) expressed as the reduction of the number of abdominal constrictions between control animals (acetic acid treated mice) and mice pretreated with the extract. Aspirin (100 $\mathrm{mg} \mathrm{kg}^{-1}$, i.p.) was used as standard.

\section{Antipyretic activity}

Yeast induced hyperthermia: About 5 groups of 6 rats each were injected subcutaneously with $10 \mathrm{~mL} \mathrm{~kg}^{-1}$ body weight. Yeast suspension (15\% aqueous suspension) to induce pyrexia after measuring the basal rectal temperature of each animal. About $19 \mathrm{~h}$ after yeast injection, the rectal temperature was recorded again and animals showing a rise in temperature of $<0.6^{\circ} \mathrm{C}$ were discarded (Mukherjee et al., 2002). Rectal temperatures were then recorded at $20-24 \mathrm{~h}\left(\mathrm{~T}^{\circ} \mathrm{C}\right)$ after yeast injection. Then MEMI was administered orally at doses of 50, 100 and $200 \mathrm{mg} \mathrm{kg}^{-1}$ body weight to three groups of animals, respectively. About 10\% Propylene glycol $\left(5 \mathrm{~mL} \mathrm{~kg}^{-1}\right.$, body weight) was administered orally to the control group of animals. The 5th group of animals received the standard drug paracetamol (100 $\mathrm{mg} \mathrm{kg}^{-1}$, body weight.) orally. Rats were restrained for recording of their rectal temperatures at intervals of $1 \mathrm{~h}$ after the drug administration.

Statistical analysis: The data were analyzed for significance using the unpaired two-tailed student's t-test.

\section{RESULTS}

The results from the present study show that the crude extract of $M$. indica exhibited activities in various degrees against inflammation, pain and fever.

\section{Studies on inflammation}

Acute inflammation study: Carrageenan induced rat paw oedema was markedly inhibited by intraperitonial treatment with either the extracts $\left(50-200 \mathrm{mg} \mathrm{kg}^{-1}\right)$. 
Int. J. Mol. Med. Adv. Sci., 6 (2): 26-30, 2010

Table 1: Effect of oral administration of MEMI on carrageenan induced right hind paw oedema in wistar rats Increase in paw oedema volume $(\mathrm{mL})$

\begin{tabular}{|c|c|c|c|c|c|c|}
\hline \multirow[b]{2}{*}{$\underline{\text { Treatment group }}$} & \multirow[b]{2}{*}{ Dose $\left(\mathrm{mg} \mathrm{kg}^{-1}\right)$} & & & & & \\
\hline & & $1 \mathrm{~h}$ & $2 \mathrm{~h}$ & $3 \mathrm{~h}$ & $4 \mathrm{~h}$ & $5 \mathrm{~h}$ \\
\hline Control & - & $0.60 \pm 0.03(0.00)$ & $1.14 \pm 0.05(0.00)$ & $1.84 \pm 0.10(0.00)$ & $2.10 \pm 0.15(0.00)$ & $2.52 \pm 0.18(0.00)$ \\
\hline MEMI & 50 & $0.25 \pm 0.007(34.21)$ & $0.36 \pm 0.01(47.05)$ & $0.25 \pm 0.018(60.3)$ & $0.26 \pm 0.010(55.17)$ & $0.32 \pm 0.003(44.82)$ \\
\hline MEMI & 100 & $0.31 \pm 0.003(18.42)$ & $0.22 \pm 0.014(44.11)$ & $0.24 \pm 0.015(64.70)$ & $0.25 \pm 0.015(60.31)$ & $0.32 \pm 0.004(44.08)$ \\
\hline MEMI & 200 & $0.32 \pm 0.008(15.78)$ & $0.31 \pm 0.003(18.42)$ & $0.22 \pm 0.007(67.64)$ & $0.20 \pm 0.004(68.25)$ & $0.19 \pm 0.009(67.24)$ \\
\hline Indomethacin & 10 & $0.12 \pm 0.07(65.00)$ & $0.34 \pm 0.04(70.17)$ & $0.46 \pm 0.04(75.0)$ & $0.50 \pm 0.07(76.23)$ & $0.62 \pm 0.08(75.30)$ \\
\hline
\end{tabular}

Percentage inhibitions are indicated in brackets

Table 2: Effect of oral administration of MEMI on abdominal concentrations induced by interperitoneal injection of acetic acid in wistar rats

\begin{tabular}{lccc}
$\begin{array}{l}\text { Treatment } \\
\text { group }\end{array}$ & $\begin{array}{c}\text { Dose }\left(\mathrm{mg} \mathrm{kg}^{-1},\right. \\
\text { body weight) }\end{array}$ & $\begin{array}{c}\text { Number of writhes } \\
\text { (per 30 min) }\end{array}$ & $\begin{array}{c}\text { Inhibition of } \\
\text { writhing response }\end{array}$ \\
Control & - & $32.33 \pm 2.71$ & - \\
MEMI & 50 & $30.67 \pm 2.84$ & 35.66 \\
MEMI & 100 & $19.33 \pm 1.56$ & 59.45 \\
MEMI & 200 & $18.83 \pm 4.02$ & 64.96 \\
Aspirin & 100 & $11.00 \pm 1.40$ & 66.00 \\
\hline
\end{tabular}

Various extracts of $M$. indica showed highly significant $(\mathrm{p}<0.001)$ acute inflammatory effect in a dose related manner. The results were shown in the Table 1.

\section{Antinociceptive activity}

Acetic acid induced writhing in mice: The methanolic extracts (50-200 $\mathrm{mg} \mathrm{kg}^{-1}$, i.p.) were significantly reduced $(\mathrm{p}<0.001)$ acetic acid induced abdominal constrictions and stretching of hind limbs in a dose-dependent manner (Table 2).

Antipyretic activity: As shown in Table 3 subcutaneous injection of yeast caused elevation of rectal temperature in control rats $19 \mathrm{~h}$ after administration. Oral administration of the extracts produced a significant $(\mathrm{p}<0.001)$ dose dependent inhibition of temperature elevation. Peak inhibitory effect was observed at $1 \mathrm{~h}$ post-therapy, i.e., $21 \mathrm{~h}$ post-yeast injection $(\mathrm{p}<0.001)$.

\section{DISCUSSION}

Among several traditional claims, the usefulness of $M$. indica in fever, inflammation and pain have been emphasized more in literature. Hence it was considered that investigations for these medicinal properties might give scientific authentication to the traditional claims. Moreover, this plant has not been subjected to above mentioned systemic pharmacological screening so far.

In the present study, the anti-inflammatory, analgesic and anti-pyretic activity of the crude methanolic extracts of $M$. indica has been established. The test extracts at three different doses $\left(50,100\right.$ and $\left.200 \mathrm{mg} \mathrm{kg}^{-1}\right)$ were found to significantly inhibit the Carrageenan-induced rat paw oedema, a test which has significant predictive value for anti-inflammatory agents acting by inhibiting the mediators of acute inflammation (Mossa et al., 1995).
Oedema formation due to carrageenan in the rat paw is the biphasic event (Vinegar et al., 1969). The initial phase is attributed to the release of histamine and serotonin (Crunkhorn and Meacock, 1971). The second phase of oedema is due to release of prostaglandins, protease and lysosome. The second phase is sensitive to most clinically effective anti-inflammatory drugs (Vineger et al., 1969; Di Rosa et al., 1971). Besides in the carrageenaninduced rat paw oedema model the production of protanoides has been through the serum expression of COX-2 by a positive feedback mechanism (Nantel et al., 1999). Therefore, it is suggested that the mechanism of action of test extracts may be related to prostaglandin synthesis inhibition as described for the anti-inflammatory mechanism of non-steroidal anti-inflammatory drugs in the inhibition of inflammatory process induced by carrageenan.

In addition, the classification of antinociceptive drugs is usually based on their mechanism of action either on the central nervous system or on the peripheral nervous system (Planas et al., 2000). With respect to the writhing test the research group of Derardt et al. (1980) described the quantification of prostaglandins by radio immuno assay in the peritoneal exudates of rats obtained after intra peritoneal injection of acetic acid. They found high levels of prostaglandins, PGE2 and PGF2 alpha during the first $30 \mathrm{~min}$ after acetic acid injection. Nevertheless, it was found that the intra peritoneal administration of acetic acid-induces the liberation not only of prostaglandins but also of the sympathetic nervous system mediators (Hokansan, 1978).

Thus, the results obtained for the writhing test using acetic acid are similar to those obtained for the odematogenic test using carrageenan. Therefore, antiinflammatory substances may also be involved in the peripheral analgesic activity.

Indeed, Non-Steroidal Anti-Inflammatory Drugs (NSAIDP) like paracetamol, exert their antipyretic action by largely inhibiting prostaglandin (E-type) protection in the hypothalamus (Rang et al., 1999). Consequently, elevated plasma prostaglandin level as observed in fever is suppressed. Acetyl salicylic acid, another reference anti-pyretic drug (not used in this study) also brings about the same effect by a selective action on a specific 
Int. J. Mol. Med. Adv. Sci., 6 (2): 26-30, 2010

Table 3: Effect of oral administration of MEMI on yeast induced pyresis in wistar rats

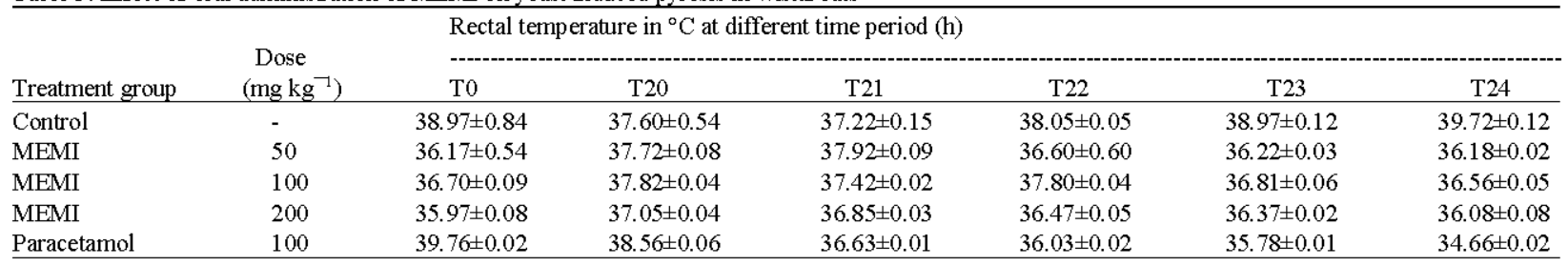

Cyclo-Oxygenase (COX) isoenzyme in the CNS. The crude methanolic extracts of $M$. indica demonstrated effective anti pyretic activity as evident in the inhibition of the temperature elevation in the yeast model. The antipyretic action of the extract may possibly be through inhibition of prostaglandin production, leading to suppression of elevated plasma level especially since the extract had been shown to possess analgesic and anti-inflammatory activities.

\section{CONCLUSION}

From these investigations it may be concluded that the crude methanolic extracts of $M$. indica showed analgesic, anti-inflammatory and antipyretic effects, similar to those observed for non-steroidal drugs such as phenyl butazone and paracetamol. It is important to point out that the phytochemical analysis showed the presence of flavonoids and this might be responsible for anti-inflammatory and analgesic activity. Further investigations are under process in the laboratory to isolate and characterize the specific active components of the plant extract which is responsible for observed pharmacological actions.

\section{REFERENCES}

Acharya, D. and A. Shrivastava, 2008. Indigenous Herbal Medicines: Tribal Formulations and Traditional Herbal Practices. 1st Edn., Aavishkar Publishers, Distributors, Jaipur, India, ISBN-13: 9788179102527.

Chu, D. and B.A. Kovacs, 1977. Anti-inflammatory activity in oak gall extracts. Arch. Int. Pharm. Ther., 230: $166-176$.

Crunkhorn, P. and S.C.R. Meacock, 1971. Mediators of the inflammation induced in the rat paw by carrageenin. Br. J. Pharmacol., 42: 392-402.

Derardt, R., S. Jougney, F. Delevaliee and M. Flahaut, 1980. Release of prostaglandins $\mathrm{E}$ and $\mathrm{F}$ in an algogenic reaction and its inhibition. Eur. J. Pharmacol., 61: 17-24.

Di Rosa, M., J.P. Giroud and D.A. Willough, 1971. Studies of the acute inflammatory response induced in rats in different sites by carrageenan and turpentine. Pathology, 104: 15-29.
Goldenberg, M.M. and A.C. IIse, 1977. Anti-inflammatory activity in EU-2972, 2-(3,4-di chlorophenyl amino) quinazolinium bromide. Arch. Int. Pharm. Ther., 228: 153-161.

Golshani, S., F. Karamkhani, H.R. Monsef-Esfehani and M. Abdollahi, 2004. Antinociceptive effects of the essential oil of Dracocephalum kotschyi in the mouse writhing test. J. Pharm. Pharm. Sci., 7: 76-79.

Hokansan, G.C., 1978. Acetic acid for analgesic screening. J. Natl. Prod., 41: 497-498.

Koster, R., M. Anderson and E.J. De Beer, 1959. Acetic acid for analgesic screening. Fed. Proc., 18: 412-418.

Kuhn, M.A. and D. Winston, 2000. Herbal Therapy and Supplements a Scientific and Traditional Approach. Lippincott, New York, pp: 2-15.

Lai, P.K. and J. Roy, 2004. Antimicrobial and chemopreventive properties of herbs and spices. Curr. Med. Chem., 11: 1451-1460.

Monsef-Esfahani, H.R., A. Ghobadi, M. Iranshahi and M. Abdollahi, 2004. Antinociceptive effect of harmala. L alkaloid extract on mouse formalin test. J. Pharm. Pharm. Sci., 7: 65-69.

Mossa, J.S., S. Rafatullah, A.M. Galal and M.A. Al-Yahya, 1995. Pharmacological studies of rhus retinorrhaea. Int. J. Pharmacognosy, 33: 242-246.

Mukherjee, K., B.P. Saha and P.K. Mukherjee, 2002. Evaluation of antipyretic potential of Leucas lavandulaefolia (Labiatae) aerial part extract. Phytother. Res., 16: 686-688.

Nadkarni, K.M., 1954. Indian Materia Medica. 3rd Edn., Popular Books, Bombay.

Nantel, F., D. Denis, R. Gordon, A. Northey, M. Cirino, K.M. Metters and C.C. Chan, 1999. Distribution and regulation of cyclo-oxygenase-2 in carrageenaninduced inflammation. Br. J. Pharmacol., 128: 853-859.

Planas, E., S. Sanchez, L. Rodriguez, O. Pol and M.M. Puig et al., 2000. Antinociceptive, antiedema effects of liposomal morphine during acute inflammation of the rat paw. Pharmacology, 60: 121-127.

Ramadan, M.F., G. Sharanabasappa, S. Parmjyothi, M. Seshgiri and J.T. Moersel, 2006. Profile and levels of fatty acids abd bioactive constituents in mahua butter from fruit seeds of butter cup tree (Madhuca longifolia (Koenig)). Eur. Food Res. Technol., 222: 710-718. 
Rang, H.P., M.M. Dale and J.M. Ritter, 1999. AntiInflammatory and Immunosuppressant Drugs: Pharmacology. 4th Edn., Churchill Levingstone, Edinburgh.

Tapsell, L.C., I. Hemphill, L. Cobiac, C.S. Patch and D.R. Sullivan et al., 2006. Health benefits of herbs and spices: The past, the present, the future. Med. J. Aust., 185: S4-S24.

Varier, P.S.V., 1995. Indian Medicinal Plants. Orient Longman, Arya Vaidyasala Kottakkal, pp: 362.

Vinegar, R., W. Schreiber and R. Hugo, 1969. Biphase development of carrageenan oedema in rats. J. Pharm. Exp. Ther., 166: 96-103.
Winter, C.A., E.A. Risley and G.W. Nuss, 1962. Carrageenan-induced oedema in hind paw of the rats as assay for anti-inflammatory drugs. Proc. Soc. Exp. Biol. Med., 111: 544-547.

Yoshikawa, K., M. Tanka, S. Arihara, B.S. Pal, S.K. Roy, E. Matsumura and S. Katayama, 2000. New oleanene triterpenoid saponins from Madhuca indica. J. Nat. Prod., 63: 1679-1681.

Yosiokal, I., A. Inada and I. Kitagawa, 1974. Structures of genuine sapogenol protobassic acid and a prosapogenol of seed kernels of Madhuca indica. Tetrahedron, 30: 707-714. 